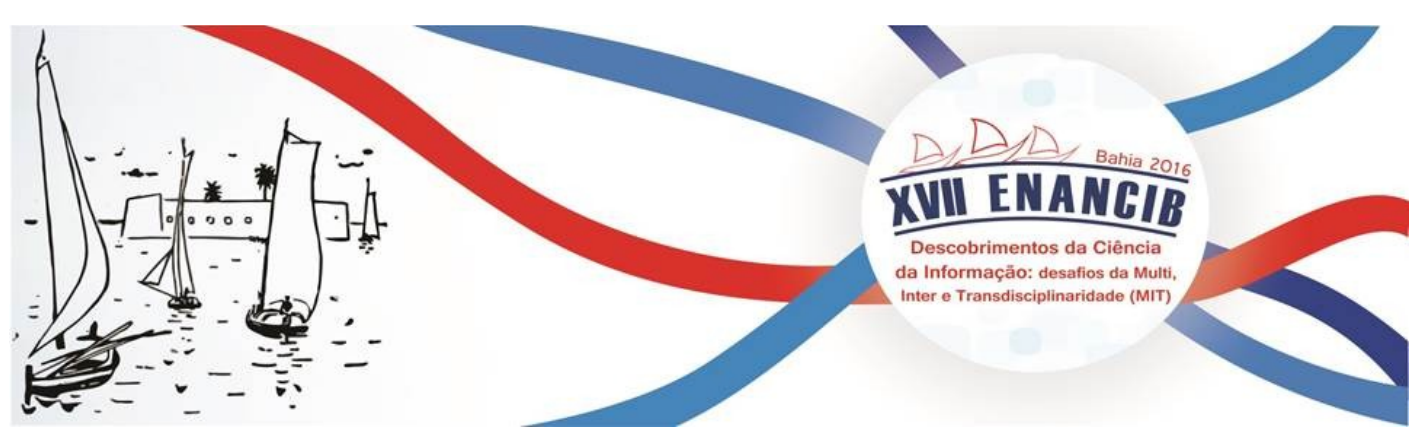

XVII Encontro Nacional de Pesquisa em Ciência da Informação (XVII ENANCIB)

\author{
GT 6 - Informação, Educação e Trabalho
}

\title{
ESTUDO BIBLIOMÉTRICO DAS PUBLICAÇÕES DO GT6 - ENANCIB: ANÁLISE DO TERMO COMPETÊNCIA
}

\author{
STUDY OF BIBLIOMETRIC GT6 PUBLICATIONS - ENANCIB: \\ ANALYSIS OF THE TERM COMPETENCE
}

Gabriela Belmont Farias ${ }^{1}$, Maria Giovanna Guedes de Farias ${ }^{2}$

Modalidade da apresentação: Comunicação Oral

\begin{abstract}
Resumo: Trata-se de pesquisa realizada na coleção Benancib depositada no repositório Questões em Rede, do Grupo de Pesquisa Informação, Discurso e Memória, da Universidade Federal Fluminense. Tal coleção disponibiliza a produção científica do Encontro Nacional de Pesquisa e Pós-Graduação em Ciência da Informação (Enancib). O objetivo foi analisar, no período de 2005 a 2014, a recorrência do termo competência no campo de busca título, palavras-chave, para então, ao recuperar as publicações, averiguar quais autores e instituições mais publicaram nesse lapso de tempo, bem como quais são as temáticas mais recorrentes nesses dez anos escolhidos. A pesquisa configura-se por uma abordagem quanti-qualitativa, com característica descritivo-exploratória. Em relação ao procedimento para a elaboração e execução da pesquisa foi escolhido o método denominado bibliometria. Os resultados mostraram a predominância de trabalhos publicados no grupo de trabalho Informação, Educação e Trabalho (GT6), entretanto esse termo aparece também nos títulos de produções de outros GT's. Ademais, percebeu-se que os autores mais recorrentes em sua maioria sempre participaram do GT6, publicando em parceria com outros pesquisadores e com seus orientandos. As temáticas mais abordadas foram: competência, competência em informação, educação continuada, formação e perfil profissional. Conclui-se que, essa análise fornece elementos que podem ser utilizados para refletir, sobre de que forma a competência vem sendo abordada na Ciência da Informação no Brasil.
\end{abstract}

Palavras-chave: Competência. Competência em Informação. Formação Profissional. Coleção Benancib. Enancib.

Abstract: This is research conducted in the Benancib collection deposited in the repository Issues Network, the Research Group Information, Speech and Memory of the University Federal Fluminense. This collection provides the scientific production of the National Meeting of Research and Graduate

\footnotetext{
${ }^{1}$ Doutora em Ciência da Informação do Departamento de Ciência da Informação. Programa de PósGraduação em Ciência da Informação - PPGCl/UFC.

${ }^{2}$ Doutora em Ciência da Informação do Departamento de Ciência da Informação. Programa de PósGraduação em Ciência da Informação - PPGCI/UFC
} 
Diploma in Information Science (Enancib). The aim was to analyze, from 2005 to 2014, the recurrence of the term competence in the title search field, keywords, and then, when retrieving publications, find out which authors and institutions more published this lapse of time, and which are the most recurrent themes in these chosen ten years. The research set up by a quantitative and qualitative approach is descriptive exploratory feature. Regarding the procedure for the preparation and execution of the research was the method called bibliometrics chosen. The results showed the predominance of papers published in the workgroup information, education and work (GT6), but this term also appears in the titles of other GT's productions. Furthermore, it was realized that the most recurrent authors mostly always participated in the GT6, publishing in partnership with other researchers and with their mentees. More topics addressed were: competence, information literacy, continuing education, training and professional profile. In conclusion, this analysis provides elements that can be used to reflect on how the power is being addressed in Information Science in Brazil.

Keywords: Competence. Information literacy. Professional qualification. Collection Benancib. Enancib.

\section{INTRODUÇÃO}

O tema competência tem estado presente nas discussões acadêmicas, nos últimos anos, associado a diferentes instâncias de compreensão: no nível da pessoa (a competência do indivíduo), das organizações (as competências organizacionais e as core competences) e dos países (sistemas educacionais e formação de competências). Segundo Vasconcelos (2010), essa discussão tem ocorrido, principalmente, em função das situações profissionais serem cada vez mais imprevisíveis, a partir da realidade complexa e mutável que se apresenta.

Nessa perspectiva, observando a importante relação existente entre o conceito de competência e o de competência em informação (CoInfo), e considerando as mudanças ocasionadas pelo dinâmico processo da globalização, faz-se necessário repensar também o que precisa ser modificado e aperfeiçoado nos processos educacionais e de formação de competências, tendo em vista a necessidade do acompanhamento dos avanços tecnológicos e científicos.

Assim, o que se observa é que a aplicação do conceito de ambos os termos podem ser considerados relativamente complexos, tendo em vista o interesse pelo assunto nas últimas décadas, bem como pela realização de diversos estudos empíricos, especialmente pela difusão de diversos modelos que envolvem a temática nas suas três esferas de compreensão. A abrangência e relevância do tema legitimam o mapeamento de pesquisas na área, o que para os pesquisadores do campo tem caráter instrumental.

Diante do exposto, o presente estudo caracteriza-se como bibliométrico, pois objetiva apresentar um panorama da temática competência presente nas publicações reunidas nos últimos dez anos (2005 - 2014) na coleção Benancib, a qual disponibiliza a produção 
científica do Enancib, e que está hospedada no repositório Questões em Rede. A escolha da Bibliometria se justifica nesta pesquisa, pois se tencionou mapear o termo competência e seus desdobramentos do GT6, com a finalidade de proporcionar uma visão das pesquisas realizadas na Ciência da Informação (CI) relacionadas ao desenvolvimento da educação e mercado de trabalho.

Para alcançar tal objetivo, buscou-se classificar as publicações segundo os seguintes critérios: o quantitativo de publicações com o termo competência em geral, por grupo de trabalho e depois, especificamente, do GT6; em seguida pelo quantitativo de autoria e de natureza de publicação. Foram analisadas também as abordagens temáticas e metodológicas utilizadas nas publicações do GT6 e seus respectivos autores. Dessa forma, foi possível identificar as temáticas e metodologias mais utilizadas nas publicações, bem como os autores mais recorrentes na produção científica do GT6 nos últimos dez anos.

2 COMPETÊNCIA E COMPETÊNCIA EM INFOMRAÇÃO: relações conceituais

A compreensão dos conceitos de competência e CoInfo deve ser analisada em um contexto que envolve, inclusive, questões éticas e sociais. Para Ruas (2006), a análise tem sido feita com abordagens comportamentais padronizadas - habilidades, desempenho, etc. -, que não levam em conta o processo de aprendizagem e o desenvolvimento de conhecimento. No processamento do saber, as competências são aspectos relevantes do conhecimento, a qual envolve a expertise, como o aprendizado e destreza em realizar e discernir a essencialidade do fazer.

Segundo Fleury \& Fleury (2004, p.30), competência é um saber agir responsável e reconhecido, que implica mobilizar, integrar, transferir conhecimentos, recursos, habilidades, que agreguem valor econômico à organização e valor social ao indivíduo. Para Zarifian (2003), competência é a tomada de iniciativa e responsabilidade do indivíduo em situações profissionais com as quais ele se confronta; competência é uma inteligência prática das situações, que se apoia em conhecimentos adquiridos e os transforma à medida que a diversidade das situações aumenta; competência é a faculdade de mobilizar redes de atores em volta das mesmas situações, de compartilhar desafios, de assumir áreas de responsabilidade.

Meghnagi (1998) configura a competência como sendo repertórios cognitivos (que o indivíduo possui) de natureza variada, que envolvem ações e decisões das quais resulta a qualidade do desempenho. Dutra (2001) incorpora o termo "entrega" ao conceito de competência. Para ele, as pessoas possuem determinado conjunto de conhecimentos, 
habilidades e atitudes, o que não garante que a organização vá se beneficiar diretamente deles. O termo "entrega", de acordo com este autor, refere-se ao indivíduo que sabe agir de forma responsável e é reconhecido por isso.

Tendo em vista o pensamento de Le Boterf (1998; 2003), para quem competência é um conceito em construção, coloca a competência como resultado do cruzamento de três eixos: a formação da pessoa (sua biografia e socialização), sua educação e sua experiência profissional. Essa concepção leva a supor que competência é o conjunto de aprendizagens psicossociais, comunicacionais e educacionais. Observa-se que as noções de competência abordadas por Zarifian (1998), Meghnagi (1998), Dutra (2001), Le Boterf (2003), Fleury e Fleury (2004) têm como enfoque a visão sócio-cognitivista que se fundamenta na capacidade do indivíduo de mobilizar saberes adquiridos nas instituições educacionais, na experiência de trabalho, na trajetória profissional e em práticas de socialização adquiridas durante o percurso de vida. Tais capacidades têm o objetivo de resolver problemas que emergem da prática do trabalho e assim transformar esses saberes.

A construção da competência profissional está vinculada tanto à aquisição de escolaridade quanto aos processos de aprendizagem informacionais que ocorrem em momentos e espaços distintos, como explica Meghnagi (1998); às orientações valorativas que dão suporte à inovação; ao pertencimento a uma comunidade profissional; à apropriação de um saber teórico ou um saber gerado a partir da prática.

Borges (2011) corrobora essa ideia ao afirmar que a informação e o conhecimento, ao lado da educação, da formação continuada e das competências são as alavancas e os garantidores do sucesso profissional, pois acredita-se que a educação continuada poderá contemplar as exigências provindas do mercado de trabalho. Outro elemento a garantir o diferencial competitivo do bibliotecário nesse cenário é a CoInfo, já que não basta obter informações é necessário saber utilizá-las.

Os estudos sobre CoInfo no Brasil iniciaram em 2000, tendo como precursores os pesquisadores da CI e bibliotecários. Os mais citados são: Caregnato (2000); Belluzzo (2001); Dudziak (2001); Campello (2002) e Hatsbach (2002). Após a divulgação dos trabalhos destes autores, muitas pesquisas e projetos são desenvolvidos e publicados por instituições, pesquisadores e bibliotecários.

Assim, desde 2000, o movimento pela concretização da CoInfo vem se tornando cada vez mais forte, em virtude das várias manifestações públicas realizadas, como: os eventos organizados pela IFLA e de organizações profissionais, várias declarações publicadas por diversos países, sobre a CoInfo, entre outras. No Brasil, o movimento pela consolidação da 
CoInfo vem sendo realizado mediante o desenvolvimento de atividades com o propósito de informar e formar profissionais conscientes da aplicabilidade da CoInfo em suas atividades biblioteconômicas, acadêmicas e de pesquisa.

Com base nesses elementos históricos e conceituais, os pesquisadores e bibliotecários brasileiros estabelecem diversos conceitos para CoInfo. Nesta comunicação, adotou-se a definição de Belluzzo (2005), por se considerar que atende às expectativas adotadas, a saber:

A Competência em Informação constitui-se em processo contínuo de interação e internalização de fundamentos conceituais, atitudinais e de habilidades específicas como referenciais à compreensão da informação e de sua abrangência, em busca da fluência e das capacidades necessárias à geração do conhecimento novo e sua aplicabilidade ao cotidiano das pessoas e das comunidades ao longo da vida (BELLUZZO, 2005, p.38).

Evidencia-se, nesta definição, a necessidade da pessoa aprender a produzir um conhecimento desde o procedimento inicial: a busca, a qual permeia o acesso e termina no uso eficiente da informação, seja aplicada a uma necessidade específica para a resolução de problemas e tomada de decisão, ou buscando o aprendizado contínuo, desenvolvendo competências que objetivem conhecer e usufruir do complexo ambiente informacional. (FARIAS; BELLUZZO, 2015).

Destarte, percebe-se que a complexidade de estabelecer uma conexão dos conceitos da competência e CoInfo nos ambientes educacionais e corporativos é desafiadora, pois a compreensão conceitual, muitas vezes, é limitada, prejudicando o desenvolvimento de programas educacionais ou de capacitação.

\section{METODOLOGIA}

Esta pesquisa nasceu de discussões no escopo do Grupo de Pesquisa Competência e Mediação em Ambientes de Informação (CMAI/UFC), o qual objetiva, com base em teorias fundamentadoras da competência e da mediação da informação, aprofundar as percepções teórico-práticas de docentes e discentes da área de Ciência da Informação, bem como do profissional da informação inserido no mercado do trabalho, visando debater e propor estratégias para atuação do bibliotecário em unidades de informação.

A pesquisa configura-se por uma abordagem quanti-qualitativa, por trazer primeiramente a revisão de literatura, e também por apresentar característica descritivoexploratória. Descritivo, por descrever, segundo Collis e Hussey (2005), o comportamento dos fenômenos, sendo usado para identificar e obter informações sobre as características de 
um determinado problema ou questão. E exploratória por empregar, conforme Lakatos e Marconi (1999), procedimentos sistemáticos para obtenção de dados empíricos para análise.

Em relação ao procedimento para a elaboração e execução da pesquisa foi escolhido o método denominado bibliometria. A bibliometria é uma importante "ferramenta estatística básica, utilizada na gestão da informação e do conhecimento científico e tecnológico" (GUEDES; BORSCHIVER, 2005, p.1).

Desse modo, procedeu-se com a investigação na coleção Benancib, a qual disponibiliza a produção científica do Enancib. Essa coleção está depositada no repositório do projeto de pesquisa Questões em Rede (Figura 1), do Grupo de Pesquisa Informação, Discurso e Memória da Universidade Federal Fluminense.

Figura 1 - Tela do repositório do projeto de pesquisa Questões em Rede

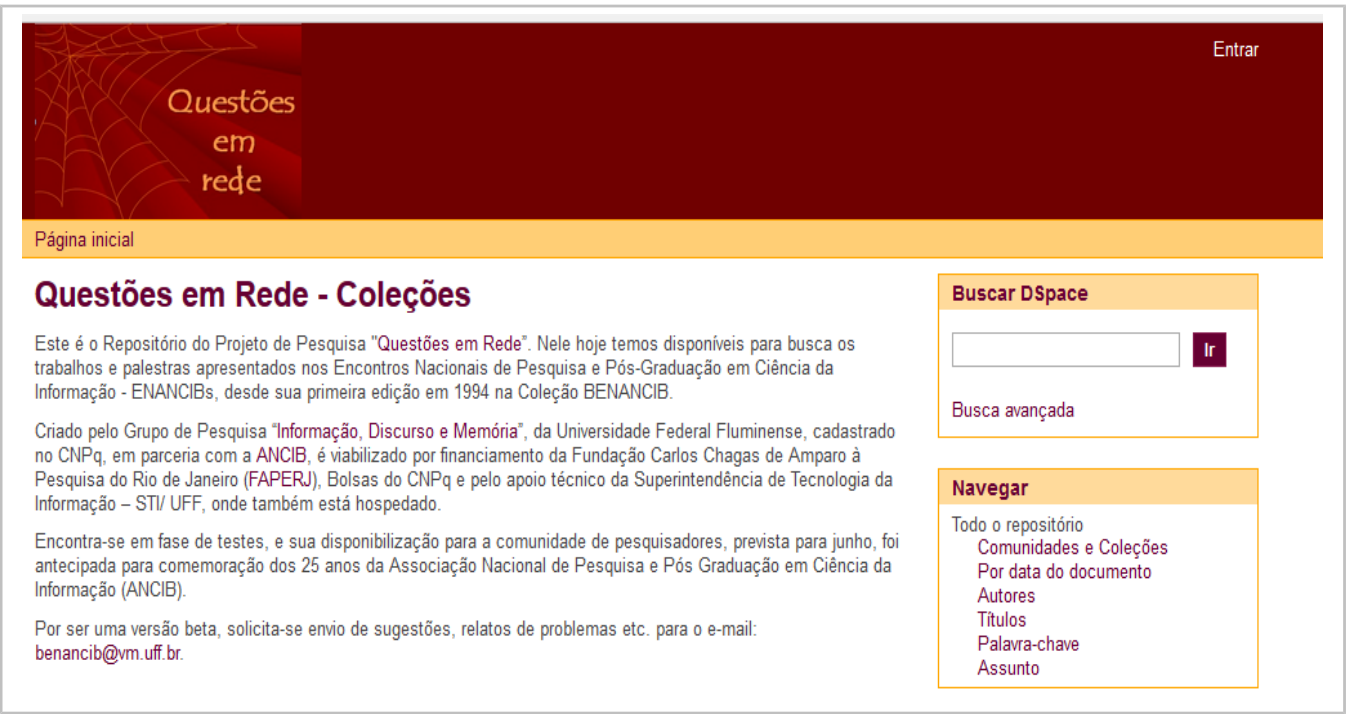

Fonte: http://repositorios.questoesemrede.uff.br/repositorios/

A pesquisa ocorreu na coleção Benancib no mês de dezembro de 2015, tendo como lapso de tempo os anos entre 2005 a 2014. A busca foi realizada pelo termo "competência", primeiro no campo título, depois no campo palavra-chave e, posteriormente, utilizando os dois campos simultaneamente. É preciso ressaltar que durante a busca, não se separou por grupo de trabalho, a intenção era descobrir em quais GT’s o termo "competência" foi utilizado, uma vez que há no Enancib um GT específico onde se trabalha a "competência", qual seja: GT6 "Informação, Educação e Trabalho”, cuja ementa, disponível no site GTAncib ressalta que: trata do estudo do campo de trabalho informacional: atores, cenários, 
competências e habilidades requeridas. Organização, processos e relações de trabalho em unidades de informação. Sociedade do Conhecimento, tecnologia e trabalho. Saúde, mercado de trabalho e ética nas profissões da informação. Perfis de educação no campo informacional. Formação profissional: limites, campos disciplinares envolvidos, paradigmas educacionais predominantes e estudo comparado de modelos curriculares. O trabalho informacional como campo de pesquisas: abordagens e metodologias.

4 RESULTADOS: apresentação e discussão

A exibição e análise dos dados têm como ponto de partida a descrição global das publicações recuperadas na coleção Benancib. Durante a busca foram recuperados 95 trabalhos. Ao visualizar o Gráfico 1, observa-se que o campo de busca "título" recuperou 14 publicações, o que representa 15\%; já o campo "palavra-chave" recuperou 17 publicações (18\%); e a busca considerando os dois campos recuperou 64 publicações (67\%). Observa-se que, ao utilizar a coleção Benancib como fonte de informação, para um maior aproveitamento dos resultados, faz-se necessário utilizar a estratégia de busca utilizando os dois campos simultaneamente.

Gráfico 1 - Resultado de Busca - BENANCIB 2005/2014

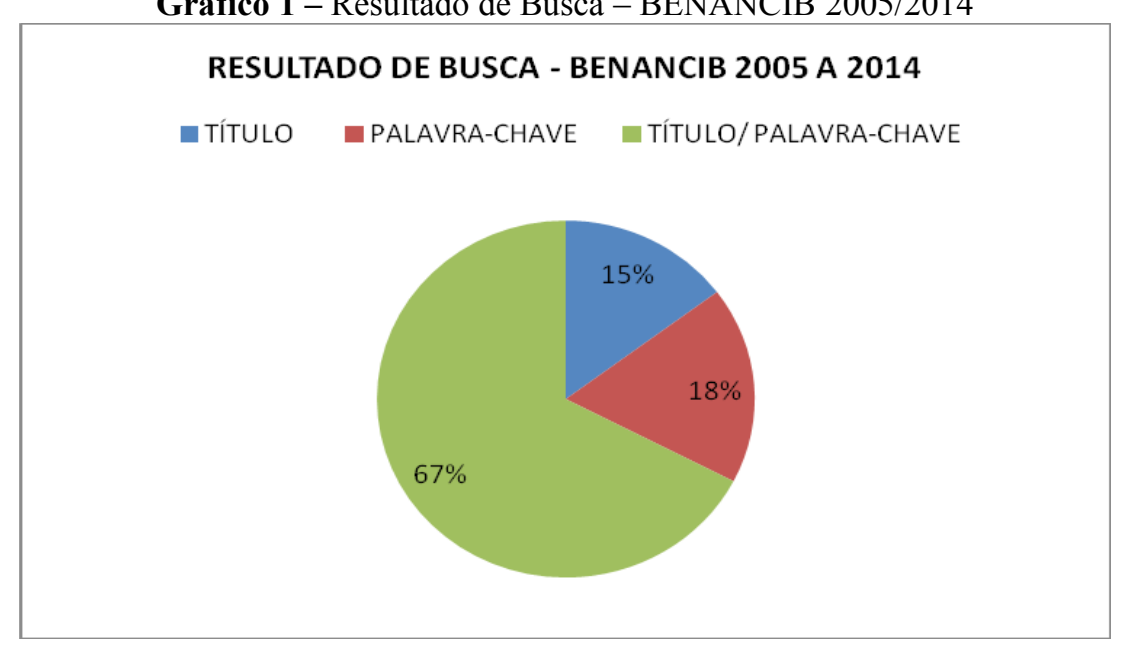

Fonte: Dados da pesquisa, 2015.

Ao visualizar os resultados do Gráfico 2, é possível observar que a maior predominância de trabalhos recuperados com o termo competência, se encontra no GT6, em 
um total de 38 (40\%) publicações; logo em seguida GT 03 - Mediação, Circulação e Apropriação da Informação com 28 (30\%) publicações; depois o GT 04 - Gestão da Informação e do Conhecimento com 15 (16\%) publicações; o GT 05 - Política e Economia da Informação com 8 (8\%) publicações; o GT 01 - Estudos Históricos e Epistemológicos da Ciência da Informação e o GT 07 - Produção e Comunicação da Informação em Ciência, Tecnologia \& Inovação ambos com 2 (2\%) publicações. O GT 08 - Informação e Tecnologia e GT 11 - Informação \& Saúde ambos com uma (1\%) publicação.

Gráfico 2 - Quantitativo de Publicação por GTs - BENANCIB 2005/2014

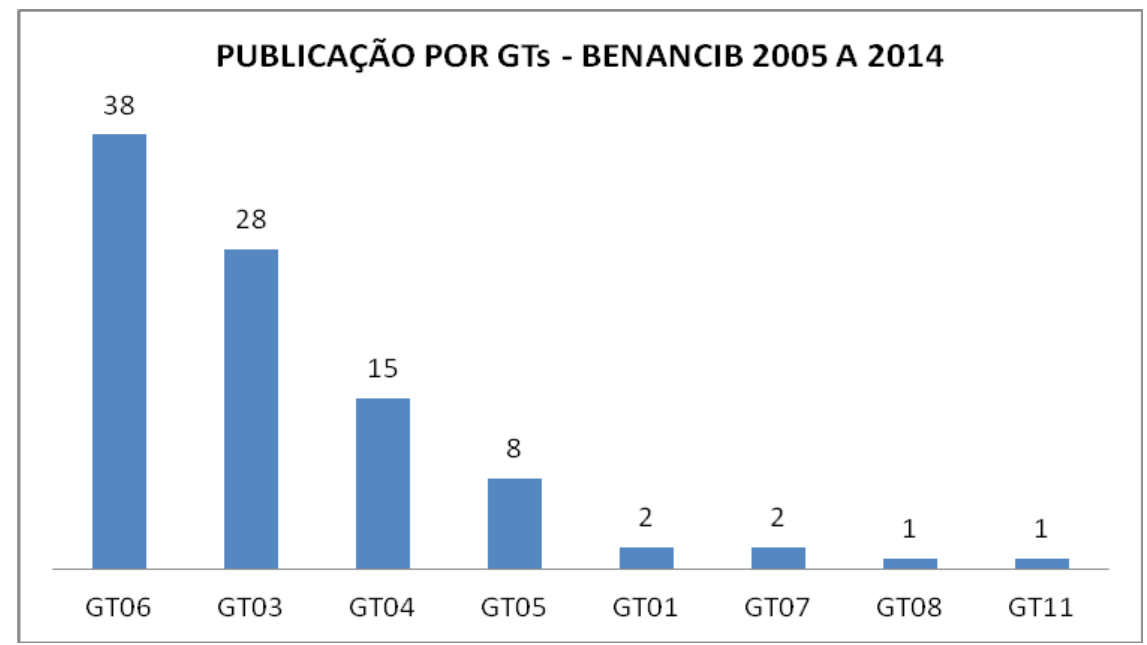

Fonte: Dados da pesquisa, 2015.

Evidencia que o termo competência é transversal tendo possibilidade de pesquisa em todos os grupos de trabalhos da Associação Nacional de Pesquisa e Pós-Graduação em Ciência da Informação (Ancib). Entretanto os GT’s 3, 4 e 6 são os que mais possuem pesquisas referentes à competência, acredita-se que isso ocorra devido à natureza e dimensões inter e transdisciplinares, envolvendo múltiplos saberes entre os GT's.

O Gráfico 3 apresenta o quantitativo relacionado à autoria das publicações recuperadas, utilizando o termo competência. Das 95 publicações recuperadas verifica-se que 57 (60\%) são elaborados por dois autores, evidenciando a prática de publicação em parceira e também das pesquisas em coautoria dos orientadores. A autoria única consta em 18 (19\%) trabalhos, um número relevante, se considerar as demandas e exigências envolvidas no ambiente e processo de pesquisa, é salutar que os pesquisadores consigam manter suas pesquisas e publicá-las 
individualmente. Ainda foram recuperados 13 (14\%) trabalhos com mais de três autores, e sete com até três autores.

Gráfico 3 - Autoria de publicação dos GT’s - BENANCIB 2005/2014

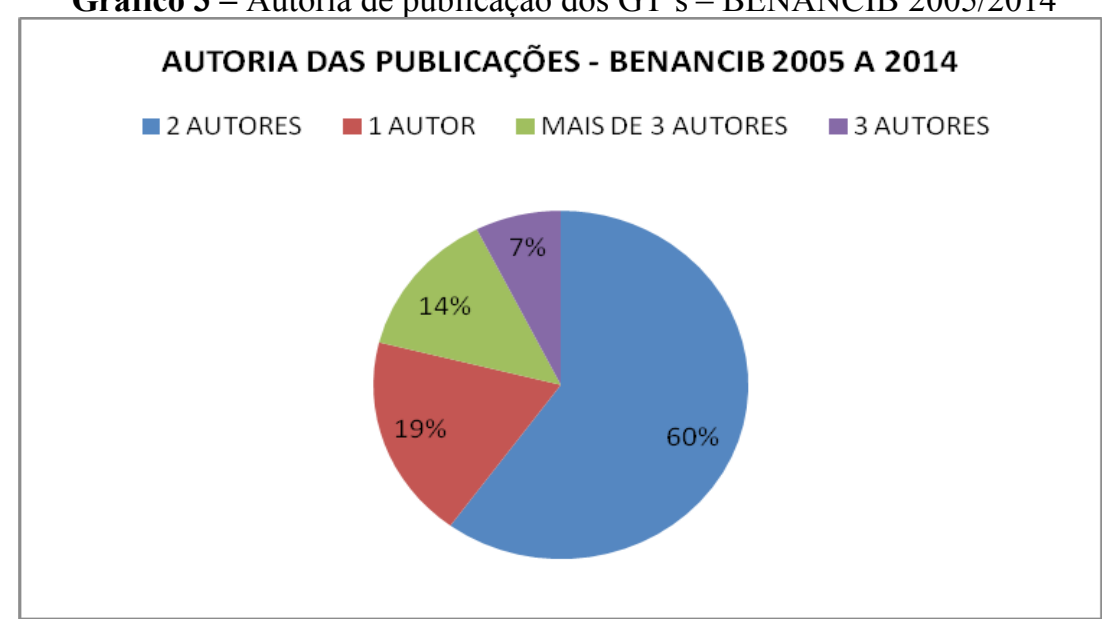

Fonte: Dados da pesquisa, 2015.

Ao proporcionar uma visão macro dos resultados recuperados na busca na coleção do Benancib, concentra-se agora na análise e apresentação dos dados do GT6. Como foi abordado no Gráfico 2, constatou-se que o GT6 possui o maior número de publicações com o termo competência totalizando 38, destas, conforme o Gráfico abaixo, 30 são publicações do tipo comunicação oral e 8 são pôsteres. Observa-se que entre os anos 2005 a 2008, 2010 a 2011 e 2013 não se recuperou nenhum pôster; enquanto em 2009, 2012 e 2014 a modalidade pôster foi um meio de divulgação de pesquisas em andamento.

Gráfico 4 - Tipo de Publicação dos GT6 - BENANCIB 2005/2014

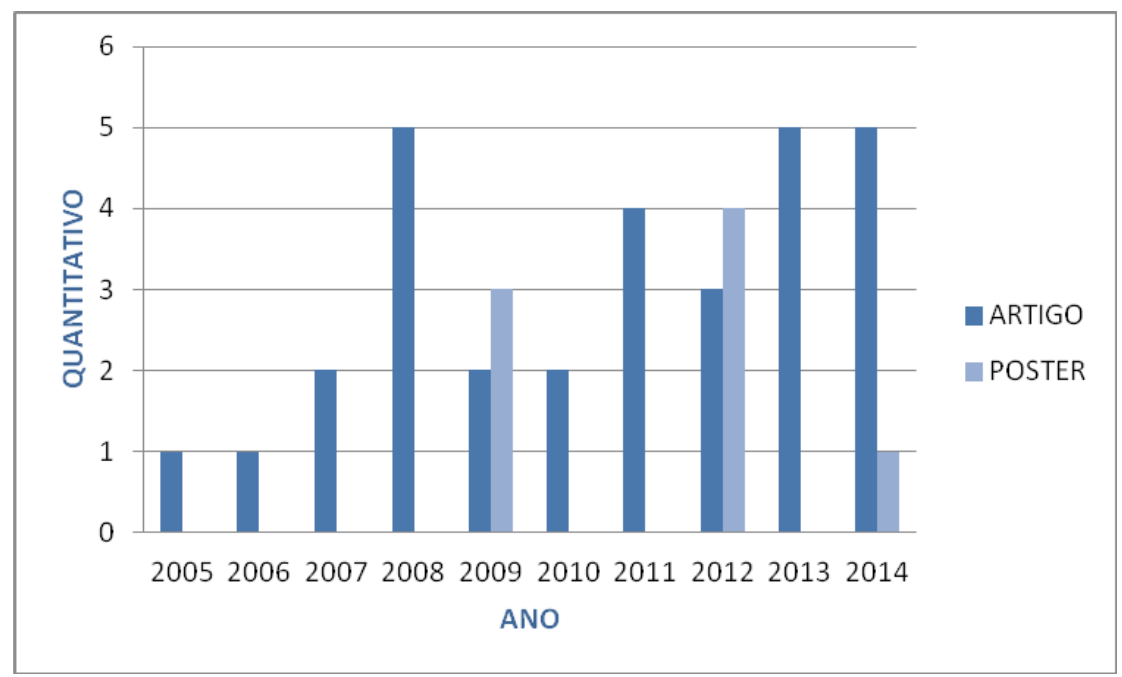

Fonte: Dados da pesquisa, 2015.

Em relação às autorias das publicações do GT6, Gráfico 5, há uma conjectura com a visão macro apresentada no Gráfico 3. Das 38 publicações recuperadas, verifica-se que 25 
(66\%) são elaborados por dois autores, evidenciando a produção de pesquisas em parceria ou em com coautoria entre orientando e orientador. A autoria única consta em sete $(18 \%)$ publicações. As publicações com mais de três autores foram cinco (13\%), sendo maior do que as publicações de até três autores (3\%).

Gráfico 5 - Autoria das Publicações dos GT6 - BENANCIB 2005/2014

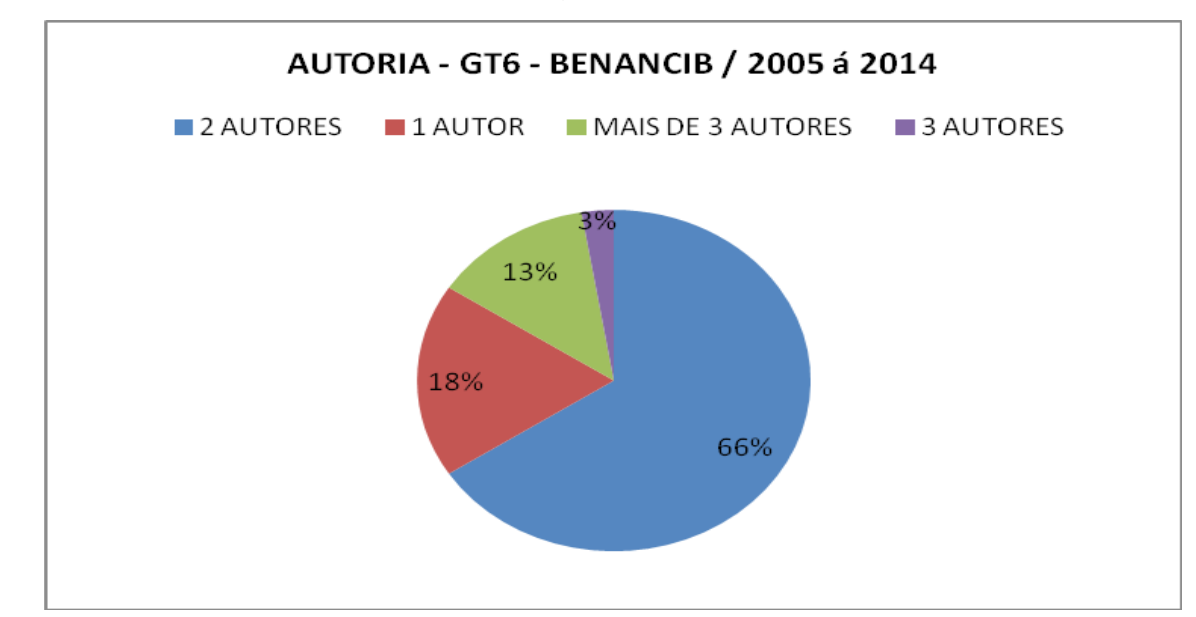

Fonte: Dados da pesquisa, 2015.

A partir dos dados coletados, criou-se o Quadro 1 para facilitar a compreensão e a análise das publicações recuperadas na coleção Benancib entre 2005 a 2014. É possível observar a relação entre: em quais anos houve o maior número de trabalhos apresentados e quais instituições publicaram suas pesquisas.

Quadro 1 - Quantitativo de Publicações dos GT6 por Ano e Instituições - BENANCIB 2005/2014 


\begin{tabular}{|c|c|c|c|c|c|c|c|c|c|c|c|}
\hline \multirow{2}{*}{ INSTITUIC̣ÃO } & \multicolumn{10}{|c|}{ PUBLICACุÃO POR ANO } & \multirow{2}{*}{ TOTAL } \\
\hline & 2005 & 2006 & 2007 & 2008 & 2009 & 2010 & 2011 & 2012 & 2013 & 2014 & \\
\hline FACEX & & & 1 & & & & & & & & 1 \\
\hline IESF & & & & & & & & 1 & & & 1 \\
\hline PUC-MINAS & & & & 1 & & & & & & & 1 \\
\hline UFBA & & & & 1 & 2 & & 1 & 2 & 1 & 2 & 9 \\
\hline UFC & & & & & & & & & & 1 & 1 \\
\hline UFF & & & & & & & & 1 & & & 1 \\
\hline UFMA & & 1 & & & & & & & & & 1 \\
\hline UFPB & & 1 & & & & & & 1 & 1 & 1 & 4 \\
\hline UFRJ-IBICT & & & & & & & 1 & & & & 1 \\
\hline UFSC & & & & 1 & & 1 & 1 & & 1 & 1 & 5 \\
\hline UFSM & & & & & 1 & & & & & & 1 \\
\hline UnB & & & & & 1 & 1 & 1 & & & & 3 \\
\hline UNESP & & & & & & & & 1 & & & 1 \\
\hline USP & & & & & & & & & & 1 & 1 \\
\hline \multicolumn{12}{|c|}{ PARCERIAS INSTITUCIONAIS } \\
\hline UFAL/UFMG & & & & & & & & & 1 & & 1 \\
\hline UFBA/UFPB & & & & & & & & & 1 & & 1 \\
\hline UFBA/UFRJ-IBICT & & & & 1 & & & & & & & 1 \\
\hline UFMA/UFRGS & & & & 1 & & & & & & & 1 \\
\hline UFSM/FAM & & & & & 1 & & & & & & 1 \\
\hline $\begin{array}{c}\text { UNICAMP/PUC- } \\
\text { CAMPINAS/CASA } \\
\text { DA SAÚDE } \\
\text { CAMPINAS/ } \\
\text { BIREME-OPAS- } \\
\text { OMS } \\
\end{array}$ & 1 & & & & & & & & & & 1 \\
\hline $\begin{array}{l}\text { USP/UNIFESP/SEC. } \\
\text { SAÚDE } \\
\text { PREFEITURA SP } \\
\end{array}$ & & & & & & & & 1 & & & 1 \\
\hline TOTAL & 1 & 2 & 1 & 5 & 5 & 2 & 4 & 7 & 5 & 6 & 38 \\
\hline
\end{tabular}

Fonte: Dados da pesquisa, 2015.

predomınancıa em publıcaçoes com o termo competencıa, quaıs sejam: Facex, IESP, PUCMinas, UFBA, UFC, UFF, UFMA, UFPB, UFRJ-Ibict, UFSC, UFSM, UnB, Unesp e USP. Em relação ao ano, a maior ocorrência foi em 2012 com sete publicações, seguido de 2014 com seis. Os anos de 2008, 2009 e 2013 com cinco publicações cada ano. Em 2011 foram quatro publicações; 2006 e 2010 com duas cada ano; 2005 e 2007 com uma publicação cada ano. Evidencia-se que as parcerias institucionais são importantes para as pesquisas no GT6, constatou-se um total de sete parcerias.

Visualiza-se no Quadro 2 as instituições que tiveram um quantitativo notável de produção em pesquisas relacionadas ao termo competência: Universidade Federal da Bahia (UFBA) com nove publicações; seguida da Universidade Federal da Paraíba (UFPB) e Universidade Federal de Santa Cataria (UFSC) com cinco publicações cada; e a Universidade de Brasília (UnB) com três publicações. 
Quadro 2 - Quantitativo de Publicações dos GT6 por Instituições, Autoria e ano - BENANCIB 2005/2014

\begin{tabular}{|c|c|c|}
\hline INSTITUIÇÃO & AUTORES & QUANTIDADE DE PUBLICAÇÃO - ANO \\
\hline \multirow{8}{*}{ UFBA } & $\begin{array}{l}\text { Kátia de Carvalho } \\
\text { Maria da Graça Gomes Almeida }\end{array}$ & $1-2008$ \\
\hline & $\begin{array}{l}\text { Aida Varela } \\
\text { Bruno B. dos Anjos } \\
\text { Igor Baraúna } \\
\text { Marilene Lobo Abreu Barbosa }\end{array}$ & $1-2009$ \\
\hline & $\begin{array}{l}\text { Aida Varela Varela } \\
\text { Marilene Lobo Abreu Barbosa } \\
\text { Joilma Maltez Silva } \\
\text { Ícaro Vinicius Costa Santos } \\
\end{array}$ & $1-2011$ \\
\hline & $\begin{array}{l}\text { Maria Giovanna Guedes Farias } \\
\text { Aida Varela Varela }\end{array}$ & $1-2012$ \\
\hline & $\begin{array}{l}\text { Aida Varela Varela } \\
\text { Marilene Lobo Abreu Barbosa } \\
\text { Ana Paula Santos Souza Teixeira } \\
\text { Ana Valéria de Jesus Moura } \\
\text { Joilma Maltez Silva } \\
\end{array}$ & $1-2012$ \\
\hline & $\begin{array}{l}\text { Marilene Lobo Abreu Barbosa } \\
\text { Aida Varela Varela }\end{array}$ & $1-2013$ \\
\hline & $\begin{array}{l}\text { Ilídio Lobato Ernesto Manhique } \\
\text { Aida Varela Varela }\end{array}$ & $1-2014$ \\
\hline & Marilene Lobo Abreu Barbosa & $1-2014$ \\
\hline $\begin{array}{l}\text { UFBA/UFRJ- } \\
\text { IBICT }\end{array}$ & $\begin{array}{l}\text { Iole Terso } \\
\text { Rubens Ribeiro Gonçalves da Silva }\end{array}$ & $1-2008$ \\
\hline UFBA/UFPB & $\begin{array}{l}\text { Maria Giovanna Guedes Farias } \\
\text { Aida Varela Varela } \\
\text { Isa Maria Freire }\end{array}$ & $1-2013$ \\
\hline \multirow{3}{*}{ UFPB } & $\begin{array}{l}\text { Isa Maria Freire } \\
\text { Gustavo Henrique de Araújo Freire }\end{array}$ & $2-(2013 ; 2014)$ \\
\hline & $\begin{array}{l}\text { Carlos Eugênio da Silva Neto } \\
\text { Gustavo Henrique de Araújo Freire }\end{array}$ & $1-2012$ \\
\hline & $\begin{array}{l}\text { Maria Meriane Vieira Rocha } \\
\text { Eliany Alvarenga de Araújo }\end{array}$ & $1-2006$ \\
\hline \multicolumn{3}{|c|}{ Continuação Quadro 2.... } \\
\hline \multirow{4}{*}{ UFSC } & $\begin{array}{l}\text { Eliane Rodrigues Mota Orelo } \\
\text { Elizete Vieira Vitorino }\end{array}$ & $1-2013$ \\
\hline & $\begin{array}{l}\text { Alexandre Pedro de Oliveira } \\
\text { Elizete Vieira Vitorino }\end{array}$ & $1-2014$ \\
\hline & Elizete Vieira Vitorino & $1-2008$ \\
\hline & $\begin{array}{l}\text { Elizete Vieira Vitorino } \\
\text { Daniela Piantola }\end{array}$ & $2-(2010 ; 2011)$ \\
\hline UnB & $\begin{array}{l}\text { Thalita Franco Santos } \\
\text { Sofia Galvão Baptista }\end{array}$ & $3-(2009 ; 2010 ; 2011)$ \\
\hline
\end{tabular}

Fonte: Dados da pesquisa, 2015.

Em relação aos autores que mais publicaram sobre o termo competência no GT6, no período de 2005 a 2014, observa-se no Quadro 2, que em primeiro lugar está Aida Varela Varela (UFBA) com sete trabalhos escritos em sua totalidade em coautoria, o que demonstra cooperação entre outros pesquisadores, bem como com seus orientandos. Na sequência têm-se Elizete Vieira Vitorino (UFSC) e Marilene Lobo Abreu Barbosa (UFBA) com cinco trabalhos cada, escritos em sua maioria em coautoria; logo após Isa Maria Freire (UFPB), Gustavo 
Henrique de Araújo Freire (UFPB), Sofia Galvão Baptista (UnB) e Thalita Franco Santos (UnB) com três trabalhos cada. É preciso destacar que a maioria destes autores publica tradicionalmente no GT6 e escreve em sua totalidade em coautoria.

Após a organização quantitativa das publicações do GT6, analisaram-se os resumos das publicações orais e pôster, a fim de identificar as temáticas abordadas no GT6, as quais foram divididas por ano. A escolha pela análise das comunicações orais e pôster ocorreu tendo em vista, que essas produções apresentam geralmente resultados de pesquisas, seja em caráter total ou parcial, permitindo ao leitor reflexões e discussões acerca do que está sendo pesquisado sobre o termo competência.

Quadro 3 - Abordagem Temática e Metodológica de 2005/2006/2007

\begin{tabular}{|l|c|l|}
\hline ANO & PUBLICAÇÃO & ABORDAGEM TEMÁTICA E METODOLÓGICA - análise do resumo \\
\hline 2005 & 1 & $\begin{array}{l}\text { - Competências desejadas ao profissional da informação para atuar na área da saúde. } \\
\text { - Método qualitativo, com abordagem exploratória. }\end{array}$ \\
\hline 2006 & 1 & $\begin{array}{l}\text { - Competência e atuação demandada aos membros que atuam em grupos de pesquisa. } \\
\text { - Pesquisa aplicada. }\end{array}$ \\
\hline \multirow{3}{*}{2007} & 1 & $\begin{array}{l}\text { - Competências informacionais dos bibliotecários que atuam junto a IES Privadas. } \\
\text { - Pesquisa de campo. }\end{array}$ \\
\cline { 2 - 4 } & 2 & $\begin{array}{l}\text { - Competências desejadas, pelo mercado de trabalho, ao profissional da informação no } \\
\text { processo de gestão da informação. } \\
\text { - Qualitativa e se utiliza do discurso do sujeito coletivo (DSC) para análise dos dados. }\end{array}$ \\
\cline { 2 - 3 } & \multirow{2}{*}{2015} &
\end{tabular}

Fonte: Dados da pesquisa, 2015.

Ao analisar o Quadro 3, observa-se que das quatro publicações apresentadas no GT6 entre 2005 a 2007 as temáticas mais recorrentes são: competência e atuação do bibliotecário em diversos nichos do mercado de trabalho sendo eles - área de saúde, grupo de pesquisa, biblioteca de instituições de ensino superior e nas organizações empresariais no processo de gestão da informação. Verifica-se que há uma predominância no uso do termo profissional da informação. Acredita-se que isso ocorra devido à influência das discussões realizadas no fim dos anos 90 e início dos anos 2000 em relação a este termo. Em relação à abordagem metodológica há predominância da qualitativa; e o tipo de pesquisa é de natureza aplicada, de campo e/ou exploratória.

Quadro 4 - Abordagem Temática e Metodológica de 2008/2009

\begin{tabular}{|c|c|l|}
\hline ANO & PUBLICAÇÃO & ABORDAGEM TEMÁTICA E METODOLÓGICA - análise do resumo \\
\hline \multirow{2}{*}{1} & $\begin{array}{l}\text { - Compreensão da Competência Informacional por meio de um debate } \\
\text { epistemológico. }\end{array}$ \\
\cline { 2 - 3 } & 1 &
\end{tabular}




\begin{tabular}{|c|c|c|}
\hline \multirow{5}{*}{2008} & & $\begin{array}{l}\text { - Formação contínua do profissional da informação para a Competência } \\
\text { Informacional na perspectiva multidimensional da informação e as dimensões } \\
\text { técnica, estética, ética e política da competência. }\end{array}$ \\
\hline & 2 & $\begin{array}{l}\text { - Avaliação da competência informacional, de estudantes de graduação, no } \\
\text { contexto de elaboração de seus trabalhos monográficos de fim de curso. } \\
\text { - estudo empírico. }\end{array}$ \\
\hline & 3 & $\begin{array}{l}\text { - Analisa a competências como forma de definir o perfil desejado para o } \\
\text { profissional da informação bibliotecário. }\end{array}$ \\
\hline & 4 & $\begin{array}{l}\text { - Analisa a função, atitudes e competências necessárias ao bibliotecário } \\
\text { médico para atuar junto às equipes médicas no processo de Medicina Baseada } \\
\text { em Evidências (MBE). } \\
\text { - pesquisa de campo com abordagem quantitativa aliada à qualitativa e análise } \\
\text { dos dados empíricos. }\end{array}$ \\
\hline & 5 & $\begin{array}{l}\text { - Analisa a relação entre informação, alfabetização informacional e } \\
\text { tecnologias da informação e comunicação (TIC) no âmbito do cotidiano do } \\
\text { profissional bibliotecário atuante em IES privadas. } \\
\text { - abordagem dialética }\end{array}$ \\
\hline \multirow[b]{2}{*}{2009} & 1 & $\begin{array}{l}\text { - Estabelecer correlações entre as diferenças de perfis de liderança e } \\
\text { desempenho. } \\
\text { - pesquisa exploratória }\end{array}$ \\
\hline & 2 & $\begin{array}{l}\text { - Discute-se o desenvolvimento de competências e capacidades } \\
\text { informacionais subjacentes no projeto pedagógico do PPGCI/UFBA, com a } \\
\text { finalidade de construir-se um lastro de conhecimentos sobre conceitos, } \\
\text { trajetórias cognitivas e mediações de competências. } \\
\text { - estudo de caso exploratório e descritivo, com uma abordagem cognitiva. }\end{array}$ \\
\hline
\end{tabular}

Fonte: Dados da pesquisa, 2015.

No Quadro 4 constam que as temáticas mais recorrentes em 2008 e 2009, quais sejam: competência em informação, formação continuada, competência, formação e perfil profissional. A competência em informação foi trabalhada em três publicações em 2008 do GT6, tendo as seguintes abordagens: compreensão epistemológica sobre CoInfo e suas dimensões técnica, estética, ética e política; a relação com a tecnologia da informação e comunicação; avaliação das habilidades informacionais de estudantes de graduação na elaboração da monografia. Esses aspectos estão relacionados à formação profisssional. $\mathrm{O}$ termo competência é apresentado em três publicações sendo: duas publicações de 2008 e em uma publicação de 2009 do GT6. As abordagens sobre competência estão relacionadas ao perfil desejado ao bibliotecário, como também a sua atuação no processo de medicina baseada em evidências, além de relacionar os aspectos implícitos do projeto pedagógico de um curso de pós-graduação no desenvolvimento de competências e capacidades informacionais.

O perfil de liderança e desempenho profissional foi abordado por uma publicação de 2009 do GT6, entretanto, a pesquisa não foi desenvolvida com bibliotecários mais com profissionais que atuam com tecnologia da informação. Em relação à metodologia utilizada predomina a abordagem qualitativa e os seguintes tipos de pesquisas: campo, descritiva, dialética, empírica e/ou exploratória. Ressaltamos que duas pesquisas de 2008, não descrevem 
em seus resumos, a metodologia empregada. Três publicações do tipo pôster de 2009 não foram possíveis de realizar a análise devido à indisponibilidade das mesmas na integra.

Quadro 5 - Abordagem Temática e Metodológica de 2010/2011

\begin{tabular}{|c|c|c|}
\hline ANO & PUBLICAÇÃO & ABORDAGEM TEMÁTICA E METODOLÓGICA - análise do resumo \\
\hline \multirow[b]{2}{*}{2010} & 1 & $\begin{array}{l}\text { - identificar as competências informacionais dos discentes em fase de } \\
\text { conclusão do curso de graduação em Biblioteconomia da Universidade } \\
\text { Federal de Goiás. } \\
\text { - abordagem quali-quantitativa }\end{array}$ \\
\hline & 2 & $\begin{array}{l}\text { - contribuir para a elaboração de um corpus teórico sobre as dimensões } \\
\text { técnica, estética, ética e política da Competência Informacional, a partir do } \\
\text { discurso dos Profissionais da Informação dirigentes de bibliotecas vinculadas } \\
\text { a IES. } \\
\text { - o discurso coletivo e representações sociais }\end{array}$ \\
\hline \multirow{4}{*}{2011} & 1 & $\begin{array}{l}\text { - identificar a competência informacional dos discentes em fase de conclusão } \\
\text { do curso de graduação em Biblioteconomia da Universidade Federal de } \\
\text { Goiás. } \\
\text { - abordagem quali-quantitativa }\end{array}$ \\
\hline & 2 & $\begin{array}{l}\text { - analisou a Competência em Informação do estudante de graduação em } \\
\text { turismo, criando uma interface entre o Turismo e a Ciência da Informação no } \\
\text { Brasil. } \\
\text { - estudo empírico }\end{array}$ \\
\hline & 3 & $\begin{array}{l}\text { - O discurso dos Profissionais da Informação dirigentes de bibliotecas } \\
\text { vinculadas a IES referentes às práticas profissionais e princípios para orientar } \\
\text { o desenvolvimento da Competência Informacional na formação inicial e } \\
\text { continuada. } \\
\text { - Discurso do Sujeito Coletivo }\end{array}$ \\
\hline & 4 & $\begin{array}{l}\text { - Analisa o domínio e o uso das tecnologias da informação e o grau de } \\
\text { apreensão da filosofia da web } 2.0 \text {, pelos usuários e bibliotecários além de } \\
\text { suas competências e habilidades segundo modelos de comportamento de } \\
\text { busca. }\end{array}$ \\
\hline
\end{tabular}

Fonte: Dados da pesquisa, 2015.

As temáticas mais recorrentes nas seis publicações do período de 2010 e 2011, apresentadas no Quadro 5, são: competência em informação relacionada à formação profissional tanto da graduação em Biblioteconomia quanto em Turismo em fase de conclusão de curso; as dimensões técnica, estética, ética e política da CoInfo, a partir do discurso dos bibliotecários dirigentes de bibliotecas vinculadas a IES; o desenvolvimento da CoInfo na formação profissional e continuada; o uso das tecnologias da informação pelos bibliotecários, além de suas competências e habilidades segundo modelos de comportamento de busca de informação. Observa-se que as duas publicações de 2010 e 2011, foram expostas com enfoques diferentes, demonstrando que as pesquisas desenvolvidas podem conter uma multiplicidade de dados a serem trabalhados com abordagens diversificadas. A metodologia utilizada é composta pela abordagem quali-qualitativa. Das seis publicações do período de 2010 e 2011 cinco não apresentam em seus resumos o tipo de pesquisa, apenas descreve que se trata de pesquisa empírica. 
Quadro 6 - Abordagem Temática e Metodológica de 2012

\begin{tabular}{|c|c|c|}
\hline ANO & PUBLICAÇÃ̃O & ABORDAGEM TEMÁTICA E METODOLÓGICA - análise do resumo \\
\hline \multirow{7}{*}{2012} & 1 & $\begin{array}{l}\text { - Discute o desenvolvimento de competências em informação para professores } \\
\text { da educação básica. } \\
\text { - A de caráter exploratório, abordagem qualitativa. }\end{array}$ \\
\hline & 2 & $\begin{array}{l}\text { - Relato da experiência da implantação de um programa voltado ao } \\
\text { desenvolvimento da competência em informação na rede municipal de saúde } \\
\text { de São Paulo. }\end{array}$ \\
\hline & 3 & $\begin{array}{l}\text { - Apresenta um modelo de mediação da informação para inclusão dos } \\
\text { moradores visando o desenvolvimento de competências informacionais. } \\
\text { - pesquisa de campo e observação participativa. }\end{array}$ \\
\hline & 4 & $\begin{array}{l}\text { - Discuti de que maneira a prática docente pode contribuir para o } \\
\text { desenvolvimento das competências e habilidades necessárias ao bacharel em } \\
\text { biblioteconomia. } \\
\text { - pesquisa social qualitativa. - análise do Discurso do Sujeito Coletivo (DSC). }\end{array}$ \\
\hline & 5 & $\begin{array}{l}\text { - Apresenta as habilidades e competências do moderno profissional } \\
\text { bibliotecário, ressaltando sua importância como mediador da informação para } \\
\text { a tomada de decisão nas organizações. } \\
\text { - pesquisa de campo exploratória, tendo o método descritivo como recurso } \\
\text { para evidenciar o problema do estudo. }\end{array}$ \\
\hline & 6 & $\begin{array}{l}\text { - Apresenta os cursos do País que têm incluído em seus currículos disciplinas } \\
\text { de competência informacional e relacionadas ao assunto, e de formação } \\
\text { pedagógica ou voltadas para a educação. } \\
\text { - estudo exploratório, utilizando-se uma abordagem quantitativa. }\end{array}$ \\
\hline & 7 & $\begin{array}{l}\text { - Apresenta as atividades voltadas para o desenvolvimento de competências e } \\
\text { habilidades para a comunidade acadêmica, pelas bibliotecas universitárias } \\
\text { brasileiras, além de identificar as competências e habilidades inerentes ao } \\
\text { bibliotecário na função de apoio à pesquisa e ao ensino. }\end{array}$ \\
\hline
\end{tabular}

Fonte: Dados da pesquisa, 2015.

As publicações de 2012 têm como temáticas recorrentes a competência em informação em quatro publicações e a competência em três publicações. Entende-se que as pesquisas envolvendo a competência, como objeto único de estudo, possui uma noção muito mais abrangente e complexa, na qual está intrínseca a competência em informação. As abordagens realizadas sobre CoInfo estão relacionadas ao desenvolvimento de habilidades informacionais de professores da educação básica, de servidores da rede municipal de saúde de São Paulo e de moradores de comunidades vulneráveis. Outro viés está ligado à formação profissional do bibliotecário, ao verificar se os currículos do cursos de Biblioteconomia possuem disciplinas que tratam da CoInfo vinculada a uma formação voltada para a educação. Evidencia-se que as publicações de 2012 apresentaram um cunho social e pedagógico da área da Biblioteconomia.

Em relação ao termo competência verifica-se que os dois trabalhos apresentados, abordam a influência da prática docente, no desenvolvimento de habilidades durante a formação do bibliotecário. O termo mediador e mediação da informação são incorporados no 
processo de desenvolvimento das competências. A abordagem metodológica é predominantemente qualitativa, e as pesquisas se classificam como sendo: aplicada, de campo, descritiva e/ou exploratória. Três publicações não apresentam em seus resumos a abordagem metodológica utilizada.

Quadro 7 - Abordagem Temática e Metodológica de 2013

\begin{tabular}{|c|c|c|}
\hline ANO & PUBLICAÇÃO & ABORDAGEM TEMÁTICA E METODOLÓGICA - análise do resumo \\
\hline \multirow{5}{*}{2013} & 1 & $\begin{array}{l}\text { - Apresenta dimensão estética da competência informacional. } \\
\text { - pesquisa de caráter qualitativo e exploratório, }\end{array}$ \\
\hline & 2 & $\begin{array}{l}\text { - Apresenta subsídios teórico-metodológicos para desenvolver competências } \\
\text { em informação, em sujeitos que vivem à margem da sociedade da } \\
\text { informação visando possibilitar intervenções na realidade social desses } \\
\text { sujeitos. } \\
\text { - cunho qualitativo, com utilização da pesquisa participante. }\end{array}$ \\
\hline & 3 & $\begin{array}{l}\text {-Discorre sobre a relação interdisciplinar entre Ciência da Informação e } \\
\text { Educação, destacando a questão de competências para profissionais em } \\
\text { formação, no ensino universitário. }\end{array}$ \\
\hline & 4 & $\begin{array}{l}\text { - Reflexão sobre competência e de sua aplicação e implicações na educação } \\
\text { e no mundo do trabalho na perspectiva de motivar e fundamentar propostas } \\
\text { pedagógicas dialógicas, com potencial para desenvolver competências. }\end{array}$ \\
\hline & 5 & $\begin{array}{l}\text { - Analisar a contribuição dos programas de "educação de usuários", } \\
\text { promovidos pelas bibliotecas universitárias vinculadas às Instituições } \\
\text { Federais de Ensino Superior (IFES) para o desenvolvimento de competência. } \\
\text { - método quantitativo e o qualitativo, por meio de estudo comparativo. }\end{array}$ \\
\hline
\end{tabular}

Fonte: Dados da pesquisa, 2015.

As temáticas recorrentes - competência em informação e competência, enfocadas em 2012, bem como o viés social e pedagógico da área da Biblioteconomia, também aparecem em 2013. As abordagens realizadas sobre a CoInfo estão relacionadas à dimensão estética e à intervenção da realidade social de sujeitos que vivem à margem da sociedade da informação. Já as abordagens sobre competência estão relacionadas à interdisciplinaridade da CI e da Educação, como também a programas de educação de usuários, promovidos pelas bibliotecas universitárias, ambos visando o desenvolvimento de habilidades na formação profissional e sua aplicação e implicações no mercado de trabalho na perspectiva de motivar e fundamentar propostas pedagógicas dialógicas. A abordagem metodológica mais encontrada é a quantiqualitativa, e as pesquisas são do tipo exploratória, participante e/ou comparativa. Duas publicações não apresentam em seus resumos a abordagem metodológica utilizada na pesquisa. 
Quadro 8 - Abordagem Temática e Metodológica de 2014

\begin{tabular}{|c|c|c|}
\hline ANO & PUBLICAÇÃO & ABORDAGEM TEMÁTICA E METODOLÓGICA - análise do resumo \\
\hline \multirow{6}{*}{2014} & 1 & $\begin{array}{l}\text { - Analisa a função pedagógica dos bibliotecários por meio da competência em } \\
\text { informação nas Escolas de Biblioteconomia do Nordeste. } \\
\text { - abordagem qualitativa, caracterizando-se como pesquisa bibliográfica e } \\
\text { documental. }\end{array}$ \\
\hline & 2 & $\begin{array}{l}\text { - analisa a dimensão técnica da competência informacional sob a perspectiva } \\
\text { teórica e a partir da visão dos bibliotecários de referência das Universidades. } \\
\text { - análise de conteúdo }\end{array}$ \\
\hline & 3 & $\begin{array}{l}\text { - Discuti o conceito sobre o papel de mediação e a função educativa do } \\
\text { bibliotecário. } \\
\text { - estudo bibliométrico - estudo exploratório }\end{array}$ \\
\hline & 4 & $\begin{array}{l}\text { - Relata as ações de informação em desenvolvimento entre pesquisadores e } \\
\text { aprendizes de pesquisa no desenvolvimento de competências para facilitar a } \\
\text { transmissão do conhecimento quanto para produzir e compartilhar } \\
\text { informações que representem oportunidades de criação de novos } \\
\text { conhecimentos. }\end{array}$ \\
\hline & 5 & $\begin{array}{l}\text { - Mapea os níveis de incorporação dos programas de competência } \\
\text { informacional nas bibliotecas universitárias de todas as instituições de ensino } \\
\text { superior de Moçambique. } \\
\text { - estudo descritivo e exploratório, cuja análise se baseou nas abordagens } \\
\text { quanti-qualitativa. }\end{array}$ \\
\hline & 6 & $\begin{array}{l}\text { - Apresenta os saberes, os saberes-fazeres e as atitudes que o bibliotecário } \\
\text { deve apresentar como potencial gerador de competências, a serem mobilizadas } \\
\text { na ocupação profissional ou em qualquer contingência. }\end{array}$ \\
\hline
\end{tabular}

Fonte: Dados da pesquisa, 2015.

Nas publicações de 2014 observou-se a recorrência das temáticas: competência em informação, competência e mediação. $\mathrm{O}$ viés abordado nessas temáticas está relacionado à função de mediação técnica e pedagógica do bibliotecário, tanto na formação profissional como na atuação em bibliotecas universitárias, visando o desenvolvimento de competências do bibliotecário, para facilitar a transmissão do conhecimento e para produzir e compartilhar novos conhecimentos. A abordagem metodológica é quanti-qualitativa, apresentando pesquisas do tipo: bibliográfica, bibliométrica, documental, exploratória e/ou descritiva. Três publicações não apresentam em seus resumos a abordagem metodológica utilizada na pesquisa.

A partir dos dados coletados e analisados, reflete-se que há uma consolidação no GT6 das pesquisas que escolheram a competência como objeto de estudo. Além disso, compreende-se que houve nestas pesquisas, um alinhamento teórico-conceitual baseado na ementa de tal grupo de trabalho, tendo como tendência as abordagens relacionadas ao campo de trabalho do bibliotecário (tecnologia e trabalho, mercado de trabalho, habilidades 
necessárias), e à formação profissional (limites, campos disciplinares, paradigmas educacionais e estudos curriculares).

\section{CONSIDERAÇÕES FINAIS}

O desenvolvimento desta pesquisa proporcionou elementos, que ratificam a relevância de estudos desta natureza, no que diz respeito a analisar a representatividade de uma temática a partir das produções científicas, para um determinado campo de pesquisa. No caso específico desta investigação, compreende-se a responsabilidade dos pesquisadores que publicam no Grupo de Trabalho Informação, Educação e Trabalho (GT6) em relação a produzir conhecimento sobre competência no âmbito da Ciência da Informação.

Essa produção possibilitou, a partir dos dados analisados, entender os caminhos percorridos pela competência e CoInfo como aporte conceitual e pragmático ligada a objetos diversos, durante um considerável período de tempo. Observa-se um despertar para compreender a competência em informação em toda sua complexidade, por um viés epistemológico, envolvendo a produção de sentido, os aspectos culturais e sociais de determinadas realidades, as dinâmicas dos ambientes educacionais e de trabalho.

As produções do GT6 ora analisadas trazem consigo possibilidades de se pensar os aspectos cognitivos que envolvem um processo de formação das competências necessárias aos bibliotecários e usuários, e quais instrumentos e ferramentas podem auxiliar esses profissionais a desenvolver habilidades, que tornem seu labor mais eficaz, no sentido de beneficiar a comunidade para quem ele trabalha.

Destaca-se que durante essa pesquisa planejou-se, por meio do resumo, analisar também quais as metodologias utilizadas nas produções recuperadas durante a busca. Entretanto, houve a impossibilidade, pois algumas comunicações orais não apresentaram a metodologia, um item obrigatório para um resumo informativo, cuja finalidade é: "Informar ao leitor finalidades, metodologia, resultados e conclusões do documento, de tal forma que este possa, inclusive, dispensar a consulta ao original", conforme as normas da Associação Brasileira de Normas Técnicas (ABNT - NBR 628).

Conclui-se, ressaltando-se que esta pesquisa terá prosseguimento, cujo foco se centrará no objetivo de analisar os artigos completos ora recuperados, a fim de mapear e averiguar mais profundamente as relações disciplinas e interdisciplinares que perpassam a competência e a competência em informação, bem como as temáticas com as quais esses dois termos 
dialogam mais intimamente. O intuito é procurar construir uma visão de base epistemológica do que vem sendo pesquisado na área nos últimos anos. 


\section{REFERÊNCIAS}

BELLUZZO, Regina Célia Baptista. O uso de mapas conceituais para o desenvolvimento da competência em informação. In: PASSOS, Rosemary; SANTOS, Gildenir Carolino (Org.).

Competência em informação na sociedade da aprendizagem. Bauru: Kayrós, 2005. p.2949.

. A information literacy como competência necessária à fluência científica e tecnológica na sociedade da informação: uma questão de educação. In: SIMPÓSIO DE ENGENHARIA DE PRODUÇÃO,7., 2001, Bauru. Anais... [S.1.p.: S.c.p.], 2001. v. 8; p.3242 .

BORGES, J. Participação política, internet e competências infocomunicacionais: estudo com organizações da sociedade civil de Salvador. (2011). 252 f. (Doutorado em Comunicação e Cultura Contemporâneas) - Faculdade de Comunicação, Universidade Federal da Bahia, Salvador, 2011.

BRASIL. Ministério do Trabalho e Emprego. Classificação Brasileira de Ocupações 2002. Brasília: MTE, 2002. Disponível em:< www.mtecbo.gov.br > Acesso em: 22 de Jul. de 2016.

CAMPELO, B. O movimento da competência informacional: uma perspectiva para o letramento informacional. Ciência da Informação, Brasília, v.32, n.3, p.28-37, set/dez. 2003. Disponível em: $<$ http://www.ibict.br/scionline >. Acesso em: 20 jul. 2016.

CAREGNATO, S. E. O desenvolvimento de habilidades informacionais: o papel das bibliotecas universitárias no contexto da informação digital em rede. Rev. de Bibliotecon. \& Comum., Porto Alegre,v. 8, p. 47-55, 2000. Disponível em:

$<$ http://eprints.rclis.org/1663/1/artigoRBC.pdf>. Acesso em: 02 jul.. 2016.

COLLIS, J; HUSSEY, R. Pesquisa em Administração: um guia prático para alunos de graduação e pós-graduação. 2. ed. Porto Alegre: Bookman, 2005.

DUDZIAK, E. A. Information literacy: princípios, filosofia e prática. Ciência da Informação, Brasília, v.32, n.1, p.23-35, jan/abr.2003. Disponível em:

$<<\mathrm{http}: / /$ www.ibict.br/scionline $>$. Acesso em: 20 jul. 2016.

DUTRA, Joel S. Gestão por competências: um modelo avançado para o gerenciamento de pessoas. São Paulo: Gente, 2001.

FARIAS, Gabriela Belmont de; BELLUZZO, Regina Célia Baptista. Como desenvolver a competência em informação mediada por modelagem conceitual teórico - prática: por um a aprendizagem significativa e criativa na educação. Londrina: ABECIN Editora, 2015.

FLEURY, Afonso; FLEURY, Maria Tereza Leme. Estratégias empresariais e formação de competências: um quebra-cabeça caleidoscópio da indústria brasileira. 3. ed. São Paulo:

Atlas, 2004. 
GUEDES, V. L. S; BORSCHIVER, S. Bibliometria: uma ferramenta estatística para a gestão da informação e do conhecimento, em sistemas de informação, de comunicação e de avaliação científica e tecnológica. 2005. Disponível em:

$<$ http://www.feg.unesp.br/VaniaLSGuedes.pdf>. Acesso em 10 jul. 2016.

HATSCHBACH, M. H. de L. Information literacy: aspectos conceituais e iniciativas em ambiente digital para o estudante de nível superior. Rio de Janeiro, 2002. 108f. Dissertação (Mestrado em Ciência da Informação) - UFRJ/ECO-MCT/IBICT, Rio de Janeiro, 2002.

LAKATOS, E. M.; MARCONI, M. de A. Metodologia científica. 5. ed. São Paulo: Atlas, 2009.

LE BOTERF, Guy. Competénce et navigation professionnelle. Paris: Éditions d'Organisation. 1999.

Desenvolvendo a competência dos profissionais. Porto Alegre: Artmed, 2003.

MARCONI, Marina de Andrade; LAKATOS, Eva Maria. Técnicas de pesquisa. São Paulo: Atlas, 1999.

MEGHNAGI, Saul. A competência profissional como tema de pesquisa. Educação \& Sociedade, São Paulo, v. 19, n. 64, set. 1998. Disponível em: <http://www.ibict.br/scionline >. Acesso em: 20 jul.. 2016.

RUAS, Roberto et al. Os novos horizontes da gestão: Aprendizagem organizacional e competências. $2^{\mathrm{a}}$ reimpressão. Porto Alegre: Bookman, 2006.

VASCONCELOS, A.F. Fatores que Influenciam as Competências em Docentes de Ciências Contábeis. In: ENCONTRO DA ASSOCIAÇÃO DOS PROGRAMAS DE PÓSGRADUAÇÃO EM ADMINISTRAÇÃO, 34, 2010, Rio de Janeiro. Anais... Rio de Janeiro: ANPAD, 2010.

ZARIFIAN, Philippe. O modelo de competência e suas conseqüências sobre as ocupações profissionais. In: Papéis de trabalho do grupo de trabalho sobre reestruturação produtiva da CUT. São Paulo, n.5, f.1-14, out. 1998. 